\title{
Emissivity Measurements of Road Materials
}

\section{Mario Marchetti* - Valérie MUZET ${ }^{* *}$ - Rodolphe Pitre* - Stefan Datcu $^{* * *}$ - Laurent Ibos ${ }^{* * *}$ - Jean Livet}

* Laboratoire Régional des Ponts et Chaussées de Nancy / CETE de l'EST

71, rue de la Grande Haie, 54510 Tomblaine, France

Mario.Marchetti@equipement.gouv.fr

Jean.Livet@equipement.gouv.fr

** Laboratoire Régional des Ponts et Chaussées de Strasbourg / CETE de l'EST

11, rue Jean Mentelin, Strasbourg-Koenigshoffen-BP 9, 67035 Strasbourg, France

Valérie.Muzet@equipement.gouv.fr

*** CERTES, IUT de Créteil, Université Paris XII Val de Marne

61, avenue du Général De Gaulle, 94010 Créteil cedex, France

datcu@univ-paris12.fr

ibos@univ-paris12.fr

\begin{abstract}
In the future, roads will have to tell the drivers what they are, whatever the conditions are. The accent is specially put on on-board infrared vision so as to understand how weather phenomena can change the surface of the road (presence of ice, ...). The determination of the emissivity is necessary to reach the road surface temperature. Some research has been undertaken on several conventional materials. Their emissivities were determined by the indirect method considering the conditions to apply Kirchhoff's law were met. An infrared hemispheric and isotropic source was used to create a periodic modulated heat flux to which the considered roads materials were submitted to. Measurements presented in this study have shown differences according to road structure (average particle diameter size) and composition. Emissivity measurements conducted on different salt types used for winter maintenance have shown they can be sorted according to their origin.
\end{abstract}

KEYWORDS: emissivity, winter maintenance 


\section{Introduction}

In the future, roads will have to tell the drivers what they are, whatever the conditions and the materials are (Aubert et al.). To do so and due to the few available studies, a research program is currently conducted with the Laboratoire Central des Ponts et Chaussées to characterize some physical properties of road materials. The accent is specially put on on-board infrared vision during bad driving weather conditions. To understand how weather phenomena can change the surface status of the road (presence of ice, ...) and to improve winter maintenance of roads, the determination of the emissivity of road materials is necessary. Indeed, it has been shown that a $6 \%$ modification of the emissivity of the road surface could induce a $1{ }^{\circ} \mathrm{C}$ decrease in the road surface temperature during winter time [Bettinelli et al., 2001]. Therefore, and to avoid the samples removal from roads, a portable device, developed by the CERTES laboratory in Créteil (Ibos et al., 2001, Isselet et al., 2001, Laroui et al., 2002), has been used to make measurements in a laboratory as well as on site.

\section{Materials and apparatus}

\subsection{Roads materials}

Several different materials can be found on roads, going from grass on roadsides, to steel of barriers and mixture of bitumen and stones of a given granularity for the road itself. The whole structure is supposed to be at ambient temperature. But the temperature each material can reach clearly depends on the characteristics of each, and its emissivity in particular, for a given weather condition (Figure 1).

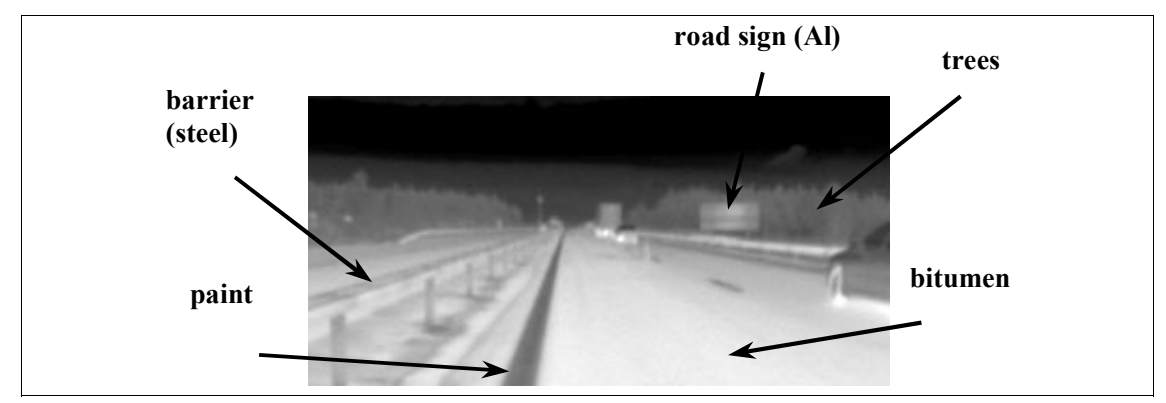

Figure 1. IR Roads surfaces structures picture (courtesy of LRPC Clermont-Ferrand) 
Several materials used in roads and highways structures were considered in this work. The first analyzed aspect was the influence of the road surface structure, i.e. a draining (permeable) one versus a granular (closed) one on the emissivity. The incidence of the three distinct geological origins of the granular material used in the making of roads was then considered. The intense use of salt in winter maintenance forced us to analyze the emissivity of this material too according to its origin. Some measurements were done on miscellaneous materials such as steel for barriers.

\subsection{Description of the experimental device (Figure 2)}

An infrared hemispheric and isotropic source was used to create a periodic modulated heat flux flow to which the samples were submitted to. This source consisted in an aluminum cube $\left(10 \times 10 \times 10 \mathrm{~cm}^{3}\right.$, with a high thermal conductivity), which bottom face has been removed. The inside of the cube is coated with a reference black paint (Nextel Velvet coating 811-21, emissivity=0.97).

The infrared modulated flow was obtained with a periodic current circulating through four Peltier modules attached to each of the five remaining faces of the cube. The amplitude of the thermal signal $\mathrm{T}(\mathrm{t})$ generated by these 20 modules never exceeded $5^{\circ} \mathrm{C}$ around room temperature. The temperature was continuously monitored using a K-type thermocouple inserted in the aluminum cube. The reflected infrared flow proportional to the hemispherical-directional reflectivity $\rho^{\text {/ }}$ of the material, is measured by a thermopile detector Dexter ${ }^{\text {TM }}$ (model 1M, 1-40 $\mu \mathrm{m}$ spectral band), delivering a voltage $\mathrm{U}(\mathrm{t})$, part of an optic chain. It collected the signal at a $15^{\circ}$ angle with the direction perpendicular to the surface sample. The infrared reflected signal is focused on the detector through a KRS5 lens, allowing the $0.6-40 \mu \mathrm{m}$ wavelength range to reach the thermopile. The thermopile footprint on the bottom side of the cube is about $0.785 \mathrm{~mm}^{2}$ of elliptic shape. This allows proper estimation of overall emissivity of rough road samples. The average granular material surface of the roughest road sample was about $5 \mathrm{~mm}^{2}$.

The system is controlled and the data collected with a computer operating with a LabVIEW $^{\mathrm{TM}}$ program. 
http://dx.doi.org/10.21611/qirt.2004.012

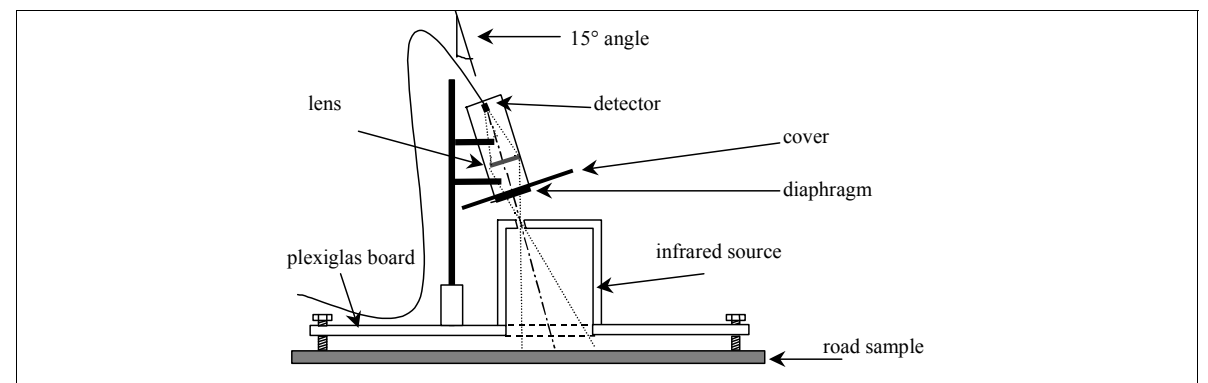

Figure 2. Portable device for emissivity measurements

\subsection{Calculation of the emissivity and experimental procedure}

The emissivity $\varepsilon$ of road materials was determined by the indirect method, measuring their reflected infrared flow. It was done considering the conditions to apply Kirchhoff's law were met (infrared source and materials were considered as grey bodies ( $\varepsilon$ independent of wavelength, and the materials and the infrared source at the same temperature). All measurements were conducted at room temperature, leading to a simplified relationship between $\varepsilon$ and the reflection coefficient:

$$
\varepsilon^{\prime}=1-\rho^{\gamma}
$$

$\rho^{\curvearrowright}$ represents the hemispherical directional reflectivity, which allows the directional emissivity, $\varepsilon^{\prime}$, calculation.

The voltage $U(t)$ of the detector, expression of the infrared flow reflected by the sample surface, can be linked to the emissivity according to equation [2]:

$$
\mathrm{U}(\mathrm{t})=\mathrm{k} \cdot \rho_{\text {sample }} \cdot \mathrm{T}_{\text {source }}{ }^{4}(\mathrm{t})
$$

$\mathrm{k}$ is a coefficient related to the detector used. It was determined by a calibration method with an 0.01 emissivity aluminum foil, and validated with the reference black paint mentioned before. Once these calibration steps performed, and since the considered material is submitted to a periodic flow at a given frequency $(12.5 \mathrm{mHz})$, a Fourier transform of equation [2] gave the emissivity of the studied material:

$$
\varepsilon_{\text {sample }}=1-\mathrm{k} \cdot \frac{\tilde{\mathrm{U}}}{\tilde{\mathrm{T}}_{\text {source }}^{4}}
$$




\section{Results}

\subsection{Influence of the thermal cycling frequency}

In order to check if emissivity measurements could depend on the thermal cycling frequency, a complete study was performed using a $15 \times 15 \mathrm{~cm}^{2}$ alumina plate (99.7 \% purity). Four thermal frequencies were considered: 5.0, 8.33, 12.5 and 25.0 $\mathrm{mHz}$. Five emissivity measurements were carried out for each frequency. The amplitude of the temperature modulation and the average of emissivity values obtained are reported in Table 1. In each case, the device calibration was done using a 0.01 emissivity aluminum foil, and the maximum voltage applied to the infrared thermal source was kept constant for all experiments.

The emissivity values obtained were quite the same for the considered frequencies. However, the emissivity uncertainty was reduced at lower frequencies. Indeed, the amplitude of the temperature modulation increased when the thermal cycling frequency is reduced. This temperature amplitude was always kept below 5 $\mathrm{K}$. So, more accurate measurements can be obtained using very low thermal cycling frequencies. Nevertheless, very low frequencies increase the experiment duration and this can be in some cases unsuitable when performing on-site measurements.

\begin{tabular}{|c|c|c|c|}
\hline $\begin{array}{c}\text { Thermal cycling } \\
\text { frequency }(\mathrm{mHz})\end{array}$ & $\begin{array}{c}\text { Thermal cycling } \\
\text { period (s) }\end{array}$ & $\begin{array}{c}\text { Amplitude of temperature } \\
\text { modulation }(\mathrm{K})\end{array}$ & Emissivity \\
\hline 25.0 & 40 & 0.85 & $0.703 \pm 0.064$ \\
\hline 12.5 & 80 & 1.8 & $0.725 \pm 0.024$ \\
\hline 8.33 & 120 & 2.65 & $0.701 \pm 0.010$ \\
\hline 5.0 & 200 & 4.2 & $0.723 \pm 0.020$ \\
\hline
\end{tabular}

Table 1. Thermal cycling frequency dependence of emissivity measurements

\subsection{Emissivity of road materials}

Averages of emissivity measurements are summarized in Table 2 . In all cases the standard deviation was lower than 0.01 . Very few differences were observed between the draining and granular surfaces. No significant difference was detected 
with the three granular materials employed in a road structure. The $\mathrm{NaCl}(98 \%)$ has the lowest emissivity among tested salts.

\begin{tabular}{|c|c|c|c|c||c|c|c|}
\hline \multicolumn{9}{|c||}{ road structures } & \multicolumn{3}{c|}{ granular structure } \\
granular structure & \multicolumn{2}{|c|}{ draining structure } & \multicolumn{3}{|c|}{} \\
\hline type $\mathrm{A}$ & type $\mathrm{C}$ & type $\mathrm{D}$ & type $\mathrm{F}$ & type $\mathrm{G}$ & Vignat & Granulac & Meilleraie \\
\hline$\varepsilon=0.97$ & $\varepsilon=0.94$ & $\varepsilon=0.93$ & $\varepsilon=0.98$ & $\varepsilon=0.99$ & $\varepsilon=0.97$ & $\varepsilon=0.98$ & $\varepsilon=0.98$ \\
\hline \hline \multicolumn{6}{|c|}{ salts used in winter maintenance } & \multicolumn{5}{c|}{ miscellaneous materials } \\
\hline $\begin{array}{c}\mathrm{NaCl} \\
(98 \%)\end{array}$ & $\mathrm{CaCl}_{2}$ & $S C P A$ type & \multicolumn{1}{c|}{$\mathrm{CSME}$ type } & $\begin{array}{c}\mathrm{Al}_{2} \mathrm{O}_{3} \\
(99.7 \%)\end{array}$ & $\begin{array}{c}\text { steel for } \\
\text { barrier }\end{array}$ & paint & grass \\
\hline$\varepsilon=0.82$ & $\varepsilon=0.95$ & $\varepsilon=0.97$ & $\varepsilon=0.97$ & $\varepsilon=0.76$ & $\varepsilon=0.60$ & $\varepsilon=0.97$ & $\varepsilon=0.93$ \\
\hline
\end{tabular}

Table 2. Emissivity measurements of road structures and materials

\section{Discussion}

Emissivity values obtained in this study were all between 0.93 and 0.98 . Several points have to be highlighted. Road samples were not smooth surfaces, as the aluminum foil or the reference black paint surfaces were. Therefore, in the same operating conditions, the measured signal with road materials was not as good compared to the ones of the calibration materials, nor as intense.

A thermal cycling frequency increase reduced the experiment duration but made the measurements less accurate, when the power amplitude is kept constant. . A high frequency might not allow the heat generated by the Peltier modules to be properly dissipated. Therefore, the generated modulation infrared flow might be lost and/or distorted, not allowing a proper determination of the emissivity. A compromise could be found between $12.5 \mathrm{mHz}$ and $25 \mathrm{mHz}$ with the current design of the portable device.

The other point is the broad spectral band of the detector $(1-20 \mu \mathrm{m})$. The emissivity obtained by the portable device is an integrated one over this large spectral band. It will not show specificities of materials in particular in spectral bands, if such specifities exist. It will improve and help the determination of thermal differences in materials used in road infrastructures. This aspect was amplified by the complex nature of road materials, which were not pure ones. As a mixture of bitumen, granular materials and sometimes additives, it then becomes impossible to sort out the contribution of each, or to detect if one has a preponderant contribution. The salts have shown promising results, indicating that their presence on roads could be detected in certain conditions. This aspect could be used in the analysis of roads' status to decide whether the application of salt is required or not. Nevertheless, the hygroscopic nature of salt makes this analysis more complex. 


\section{Conclusion}

Emissivity measurements have been performed on several road materials and some salts used in winter maintenance. No significant difference was observed for road materials within the chosen 1-40 $\mu \mathrm{m}$ spectral band, while a distinction was possible for some winter maintenance salts.

Some investigation will be conducted to find either a new detector or a wide bandpass optical filter (Ge one) with a proper and certainly narrower spectral band $(8-13 \mu \mathrm{m})$. The objective will be to select one where a distinction between road materials could be observed, and that could be used in the determination of road temperature.

\section{References}

Bettinelli J., Livet J. (2001). Etude de la contribution des propriétés physiques des diverses strutures de chausséesaux difficultés d'exploitation hivernale. LCPC-LR Nancy Report.

Aubert D., Blosseville J-M., and al. (1998). La route automatisée. Réflexions sur un mode de transport du futur. LCPC report, 89p.

Ibos L., Datcu S., Mattei S. (2001). Mesure d'émissivité totale à température ambiante de matériaux inhomogènes à l'aide d'un émissomètre portable. $V^{\text {ème }}$ Colloque Interuniversitaire Franco-Québécois (CIFQ 2001), Thermique des systèmes, Lyon, 28-30 May 2001, pp. 73-80

Isselet L., Pitre R., Muzet V. (2001). Qualification d'un émissomètre portable destiné à la détermination de l'émissivité IR des revêtements routiers. LCPC report.

Laroui A., Pitre R., Muzet V. (2002). Emissomètre portable destiné à la détermination de l'émissivité infrarouge des revêtements routiers : Qualification et premiers résultats. $L C P C$ report, $44 p$.

Especel D., Matteï S. (1996) Total emissivity measurements without use of an absolute reference. Infrared physics and technology, 37, pp. 777-784.

Siroux M., Mattei S. (1998). Une nouvelle méthode calorimétrique périodique de mesure de l'émissivité des matériaux opaques à température ambiante. Revue générale de thermique, 37 (2), pp. 103-110. 